
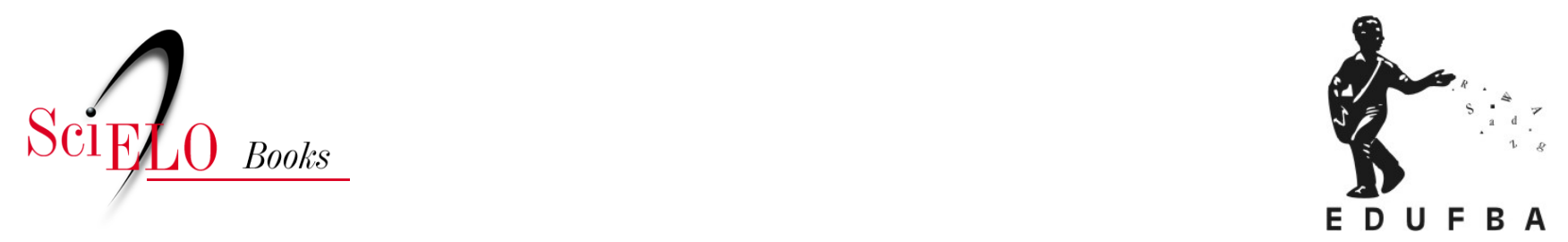

\title{
Educação mediada pelo Whatsapp ensinar e aprender por mensagens instantâneas
}

\author{
Cristiane Porto \\ Kaio Eduardo Oliveira \\ Alexandre Chagas \\ (Organizadores)
}

PORTO, C., OLIVEIRA, K.E., and CHAGAS, A., comp. Educação mediada pelo Whatsapp: ensinar e aprender por mensagens instantâneas. In: Whatsapp e educação: entre mensagens, imagens e sons [online]. Salvador: Ilhéus: EDUFBA; EDITUS, 2017, pp. 9-14. ISBN 978-85-232-2020-4. https://doi.org/10.7476/9788523220204.0001.

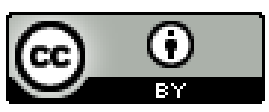

All the contents of this work, except where otherwise noted, is licensed under a Creative Commons Attribution 4.0 International license.

Todo o conteúdo deste trabalho, exceto quando houver ressalva, é publicado sob a licença Creative Commons Atribição $\underline{4.0}$. 


\section{EDUCAÇÃO MEDIADA PELO WHATSAPP: ENSINAR E APRENDER POR MENSAGENS INSTANTÂNEAS}

[...] o professor escreve na lousa a lição que deveria ser copiada por seus estudantes, que, em vez disso, preferem fotografar a lousa. Aplicam, assim, as inovaçóes tecnológicas a seu favor para tentar minimizar o monótono esforço de copiar a lição e, desse modo, ganhar mais tempo livre para poder conversar, paquerar, zoar ou mesmo explorar algumas das múltiplas funçóes de seus smartphones. (Narrativa elaborada por Oliveira, 2017)

Além de transformar a capacidade de comunicação dos usuários, as tecnologias digitais e os aplicativos de troca de mensagens, por exemplo, possibilitam um deslocamento de açóes, uma vez que ação desenvolvida nem sempre é a esperada pelo mediador ou por outros usuários. No exemplo da narrativa, a ação esperada pelo professor seria que os alunos copiassem no caderno o conteúdo escrito à lousa pelo professor, mas por um deslocamento possível pela praticidade possibilitada a partir do uso dos dispositivos móveis a ação se resume a captura de uma foto de todo o conteúdo, para ter a possiblidade de fazer outras açóes.

Esta situação descreve um procedimento que é próprio dos processos cotidianos na cultura contemporânea. Uma vez que, as práticas culturais estão permeadas de artefatos digitais que não se resumem apenas as relaçóes comunicacionais, mas a consolidação de novos modos de aprender e de acessar informação, abrindo assim a necessidade de inovação também nos modos de ensinar. Uma simples ação pode existir por meio de elementos exteriores e se consolidar em novas perspectivas no caminho, mediante as tramas da rede e das práticas culturais da cultura vigente. 
Notamos na narrativa que associaçôes rotineiras entre alunos e artefatos culturais do seu tempo, os smartphones e os aplicativos, por exemplo, criaram a possibilidade de compor um cenário de inovação à ação natural que seria copiar o texto no caderno, como imaginava a professora. No entanto, a possibilidade de se associar a dispositivos e, consequentemente, a outras pessoas, desperta um tensão à própria metodologia escolhida pelo professor para o trabalho docente, provocando um desfecho inesperado.

Quando observamos este tipo de situação, podemos avaliar que o acesso à informação e ao conhecimento na cultura digital não se produz de forma isolada e estática, está intimamente ligado também aos processos comunicativos e infocomunicacionais disponíveis e até inesperados. Contudo é preciso discutir qual o impacto do uso destes dispositivos na consolidação das práticas educativas na atualidade. Qual a potencialidade destes artefatos na medicação do trabalho docente? Como podem ser associados às metodologias de ensino e as práticas de pesquisa? Posto que, as possibilidades educacionais e comunicativas que surgem na cultura contemporânea, articuladas às mudanças sociais e ao desenvolvimento e popularização das tecnologias digitais móveis, são constantes e expressivas, ao passo que novas potencialidades também podem gerar novos problemas.

Os sites de redes sociais digitais, os jogos on-line, os sites de compartilhamento de vídeo, os gadgets e os smartphones são agora os acessórios da cultura e, mais especialmente, dos jovens. Eles estão tão associadas à vida das pessoas que é difícil lembrar que estão a disposição apenas há poucos anos. Hoje, como também foi o caso de ontem por seus antecessores, os jovens atingem a idade da busca pela autonomia, mas na cultura digital eles fazem isso por maneiras diferentes, com outros modos de comunicação, outras formas de se relacionar, novas 
formas de jogar, novas formas de expressão e também de exposição.

Diante desse cenário, experiências de ensino e aprendizagem também são possíveis em variadas configurações. Em contrapartida, algumas tensóes da prática docente e dos processos educativos surgem e colocam em questionamento os modelos de ensino mais tradicionais que, enxergam com estranhamento os hábitos na cultura vigente. Alguns estudiosos da Cibercultura afirmam a esse respeito, de modo separatista que os jovens se configuram como nativos digitais da Cibercultura e os que nasceram antes dos anos de 1990, portanto, são imigrantes digitais.

Entretanto, avançar o limite da superficialidade nos faz perceber que embora os mais jovens sejam nativos digitais e configurem suas práticas cotidianas com artefatos culturais da Cibercultura, eles não têm fluência digital para sua autoaprendizagem, necessitando assim da figura do mediador. Deste modo, o papel do professor ou de algum mediador que articule a práticas culturais da Cibercultura para a promoção da aprendizagem sempre será eficaz e relevante.

A possibilidade de fotografar, armazenar ou até mesmo encaminhar o conteúdo para outra pessoa por meio de um aplicativo de redes sociais digitais na internet possibilitam a emissão e reconfiguração de novos conteúdos. Ainda que, não intencionais se tornam disponíveis ao uso e, naturalmente, contribuem para a produção ubíqua e colaborativa de novos conteúdos por meio da reconfiguração deles, mas essas práticas por si só não garantem a aprendizagem.

Ao passo que estamos cada vez mais conectados, mais associados aos ambientes on-line e com práticas culturais cada vez mais dependentes dos aplicativos e das tecnologias digitais e da internet, desenvolvemos modos de existência híbridos. $\mathrm{O}$ aplicativo WhatsApp Messenger, tem ganhado, cada vez mais 
destaque nesse cenário, pois a possibilidade de trocar mensagens, imagens, vídeos, documentos e áudios, instantaneamente de modo gratuito tem garantido novas experiências que não se resumem as performances comunicacionais.

$\mathrm{Na}$ Cibercultura uma boa parte dos indivíduos usam suas conexóes para encontrar a informação ou para explorar os seus centros de interesses que vão além do que eles têm acesso à escola ou o que eles encontram em sua comunidade local. Grupos on-line no WhatsApp, por exemplo, permitem aos jovens de se conectarem com colegas que partilham interesses comuns. Tencionam assim, a prática de outras habilidade inerentes ao dispositivo como a escrita e leitura, mesmo em linguagem digital pelo texto escrito, pela emissão de áudio e vídeos.

A popularidade do WhatsApp é incontestável, principalmente entre os mais jovens, pelo motivo das mensagens de voz e os vídeos terem se popularizada. Mas, a marca principal do aplicativo fica por conta de sua função principal que é enviar textos (escritos ou com os emojis) e gravaçóes de áudio que são pacotes de dados mais leves e que geram menos tráfego quando comprados aos vídeos.

Com vista as potencialidades do WhatApp na Cibercultura nas páginas que se seguem evidenciamos relatos de experiências e práticas pedagógicas. Estes são resultados de pesquisa e formação construídas por meio de inquietaçóes de investigadores de grupos de pesquisas distintos e instituiçóes diversas. Assim, apresentamos este livro que tem como principal objetivo discutir a utilização do aplicativo WhatsApp como espaço de ensino, aprendizagem e formação, na Cibercultura.

Oferecemos ao leitor mais possibilidades para fazer um estudo diverso e amplo, que tem no aplicativo seu objeto de estudo e discussão e um espaço de tensão. Nas páginas as seguir apresentaremos experiências de pesquisadores, propostas de ensino e apren- 
dizagem, outras formas de ensinar e aprender que tem o WhatsApp como mediador do processo. Para que o leitor se localize com mais facilidade e, também, por julgarmos importante a divisão por temas, este livro composto com trabalho de autores do Brasil e de outros países, divide-se em três grande eixos nos quais se encontram ordenados do seguinte modo:

O primeiro tema está intitulado como "WhatsApp, Mediação e Processos Comunicativos", onde concentramos os trabalhos que se propóe a discutir o WhatsApp a partir da perspectiva comunicacional. Assim, apresentam-se experiências de como aplicativo de rede social pode mediar conexóes entre diferentes agentes em espaço-tempo distintos com um objetivo em comum, que avançam o limite do uso social.

No segundo tema estão dispostos os arquivos que se centram na temática "WhatsApp e Processos Educativos", onde reunimos os textos que apresentam o aplicativo como mediador dos processos de ensino e aprendizagem, seja na educação, formal, informal ou não-formal e que possibilitam a consolidação de novas experiências educativas.

O terceiro e último tema denominado "WhatsApp, Autoria e Prática Docente", agrupa trabalhos que discutem o WhatsApp mediante suas possiblidades de desenvolver pesquisas e auxiliar na prática docente mediante a articulação com as metodologias de ensino ou os desenhos didáticos e curriculares de cada professor.

Apesar de estarem agrupados por temáticos, é importante destacar que os trabalhos deste livro não seguem uma ordem linear. Deste modo, esperamos que os textos aqui apresentados, mesmo que lidos de modo disperso, possam contribuir ou auxiliar novas práticas de pesquisa e formação na Cibercultura e instigar também novas propostas de ensino e aprendizagem.

Acreditamos que o conjunto textual aqui delineado com seus objetivos e argumentos trazem um contributo significati- 
vo para repensarmos e inovarmos o uso do WhatsApp na educação. Seja este uso em uma proposta de educação formal ou por meio de processos formativos vinculados à educação que se constrói e se passa nos mais variados espaços sociais. O fenômeno da utilização de aplicativos que discutimos em tela por meio dos processos de comunicação em rede, nos oferece rastros suficientes para que este seja aplicado nos mais diversos e múltiplos contextos educativos, objetivando náo apenas uma inovação, mas, também, revisitando cada finalidade que este nos oferece.

Cristiane Porto

Kaio Eduardo Oliveira Alexandre Chagas

(Organizadores) 